mitzunehmen, doch waren sie nach etwa zweistündiger Rückkehr verschwunden. Wie die Eingeborenen sagten, trüge sie der Vogel, wenn er gemerkt, dass man bei dem Neste gewesen und die Eier berïhrt hätte, zu einem anderen Platze. Das Nest von Pytelìa cinereigulc, welches ich im Mai, Juni und Juli häufig in Orangenbäumen fand, gleicht den von Spermestes cucullata; aus demselben Material bestehend ist es etwa um die Hälfte umfangreicher mit seitlichem Eingange. Von Pyrenestes unicolor brüteten in diesem Jahre drei Pärchen in der Nähe der Stadt; seine Nester fand ich bisher immer nur an Cyperus befestigt. Das erste Ei ist häufig schon gelegt, wenn das Nest noch nicht ganz vollendet ist. Bei Annäherung an das Nest fliegen die Vögel hoch in die Luft steigend davon.

Von bisher auf Zanzibar noch nicht erlegten Vögeln werden Sie eine Barbatula-Art (leucolaema?) erhalten, dieselbe Art, die ich am 3. October 1878 bei Muniuni im Wapocomolande erlegte, aber wegen zu starker Schussverletzung nicht aufbewahrte. Ich hatte schon lange der eigenthümlich trillernden Flötenstimme dieses Vogels nachgespürt, ohne dass es mir gelungen wäre, den Urheber zu erlangen. Die Art hält sich hier vorzugsweise in Mangobäumen und Artocarpus auf, in welchen sie kleine Insekten von den Blättern absucht. Der Nachtreiher No. $\mathbf{4 5 5}$ findet sich in fast allen dichtdurchwachsenen Sümpfen; hier hält er sich wohlversteckt, nur zuweilen sieht man ihn auf eine kurze Strecke emporfliegen, wobei er durch die weissen Schwingen sehr auffallt.

\title{
Bitte an alle Ornithologen!
}

In Anbetracht des gemeinnützigen Zweckes, welchen wir mit nachstehendem "Compendium" verfolgen, bitten wir die Herren Collegen dringend, uns bei der mühsamen und zeitraubenden Arbeit zu unterstützen und uns die Beschreibungen oder Diagnosen - in Hinsicht auf die internationale Bedeutung sollte doch immer die lateinische Sprache benutzt werden! - der von ihnen neu publicirten Gattungen und Arten in Abschriften oder Sonderabdrücken recht zeitig zugehen zu lassen.

Dr. Ant. Reichenow. Grossbeerenstrasse 52, Berlin.
Herman Schalow. Bebren-Strasse 55, Berlin. 